\title{
The Effect of Teaching Reading Strategies Explicitly on Students' Understanding of Cohesion in Reading
}

\author{
Ali Mobalegh \\ The University of Isfahan, Isfahan, Iran \\ Email: ali_mobalegh@yahoo.com \\ Mohammad Saljooghian \\ Tehran Payam-e-Noor University, Tehran, Iran \\ Email: m.saljooghian@gmail.com
}

\begin{abstract}
Research for finding the most effective way of teaching reading is not a new area of interest in SLA; yet, it is still controversial and draws the attention of a lot of researchers and so makes it a state of art knowledge. One of the most appealing sub areas in teaching reading is instructing reading strategies and whether to teach them explicitly or implicitly. This study examined the effect of explicitly instructing reading strategies on learners' perceptions of cohesive ties in reading. These cohesive ties include reference, substitution, lexical cohesion, conjunction, and ellipses. Results suggested that this method can help improve learners' ability to perceive two aspects of cohesiveness: reference and ellipses. The three other aspects, namely conjunction, lexical cohesiveness, and substitution, have been improved as well, although not as much as they were expected to.
\end{abstract}

Index Terms - reading strategies, explicit, cohesion, learning, teaching

\section{INTRODUCTION}

The literature of Second Language Acquisition (SLA) and Foreign Language Acquisition (FLA) shows a growing interest to investigate ways for improving students' reading skills. These skills are generally called reading strategies. Reading strategies are defined as mental operations relating to how readers perceive a task, what textual cues they attend to, how they make sense of what they are reading, and what to do when they do not understand. Strategies, therefore, are readers' resources for understanding and learning (Rao et al., 2007). Since the 1970s, many language learning theorists have emphasized the importance of learning strategies in successful language learning and some have even advocated teaching students a variety of reading strategies in order to help them to read better (Cohen, 1998).

While there seems to be no arguments on implementing reading strategies to enhance readers' skills in reading, the best way to teach those skills is controversial. Some researchers believe students' attention should be drawn directly to those techniques and strategies by, say, separating the strategies from the body of readings, telling the student what those strategies are and when and where to use them; while others believe that students should learn how to use strategies by actually using them; and it's not necessary nor useful to give specific, overt instructions. The former approach is called explicit and the latter is named implicit strategy teaching (Brown, 2005).

Cohesion is one aspect of every well organized passage; and it is defined as a close relationship, based on grammar or meaning, between two parts of a sentence or a larger piece of writing (Mayor, 2009). According to Halliday and Hassan (1994) "cohesion is a semantic relation between an element in a text and some other element that is crucial to the interpretation of it." They mention that there are five kinds of cohesive ties: reference, substitution, ellipsis, conjunction, and lexical cohesion. The term reference refers to specific items within a text/discourse which are impossible to be "interpreted semantically in their own right", but "make reference to something else", i.e. some other item within the text/discourse "for their interpretation". Substitution as another type of cohesive relation, or cohesive tie, is the process in which one item within a text or discourse is replaced by another. Ellipsis, also, as a type of cohesive relation is very similar to substitution. While substitution refers to the replacement of one textual element by another, ellipsis is simply characterized by "the omission of an item". The process can, therefore, be "interpreted as that form of substitution in which [an] item is replaced by nothing" or as "substitution by zero". "Conjunctive elements are cohesive not in themselves but indirectly, by virtue of their specific meanings; they are not primarily devices for reaching out into the preceding (or following) text, but they express certain meanings which presuppose the presence of other components in the discourse". Lexical cohesion is the fifth and last type of the cohesive relations in English. It is generally understood as "the cohesive effect [that is] achieved by the selection of vocabulary". 
It is of crucial importance for every reader to be able to distinguish and identify the connections that are made to unify a reading passage if he/she wants to fully understand it. Inability to integrate the words and sentences into a coherent understanding of the text is called decoding problem. A lot of ways have been suggested to help get over this problem some of which indicate that both young and adult skilled readers make more inferences while reading (Long, et al., 1994; McNamara \& McDaniel, 2004; Oakhill \&Yuill, 1996). One very likely possibility is that poor readers somehow fail to perceive elements of cohesion of the text and subsequently cannot build over the sentences to make sense of it. This has led researchers to the conclusion that reading instruction that centers on providing guidance and training to make better inferences in reading can help readers improve their abilities (McNamara et al., 2006)

The aim of the present paper is to integrate and investigate these two important aspects of reading and their influence on one another: the effect of explicitly instructing reading strategies on learners' ability to distinguish and make sense of cohesion elements of texts. All cohesive ties have been considered and tested.

\section{BACKGROUND}

Pani (2003) in a qualitative study used mental modeling technique through which the teacher tells students what mental processes a "superior" readers use while they try to understand the text, to examine its effects on developing strategy and in turn, on students' reading comprehension. She found that this model can be effective to motivate the learners to enhance reading strategies.

Griffiths (2003) studied patterns of language strategy use and found a significant relationship between strategy use and course level according to nationality. Skilled readers turned out to use without looking up new words, avoid translating word by word, guessing the meaning through the context, and skimming respectively more than less skilled readers. Lau and Chan (2003) compared 83 good readers and 76 poor ones to study the reading strategy they use. They found that poor readers scored lower than good ones in using all those strategies, especially sophisticated cognitive and metacognitive ones.

In a research conducted by McNawara et al. (2006), an automated reading trainer called iSTART was used to investigate the effect of reading strategy training on adolescent readers' comprehension of science text. The results revealed that training students' strategies significantly leads to a better reading comprehension. Of course, students who didn't have prior knowledge of strategy use performed better on tasks which were different from the ones that students with prior knowledge of strategies did better

In another study by Boulware-Gooden et al. (2007) the effect of teaching Meta cognitive strategies was examined and through these experiments, it was revealed that metacognitive reading comprehension instruction significantly enhanced students' academic attainment. The participants of this study were children.

Another research by Rao et al. (2007) revealed that the assumption that skilled readers use reading strategies more is true for bilingual primary school students. They realized that successful learners exploited deep level processing strategies (e.g. inference, prediction, reconstruction); While less successful students used surface level processing strategies (e.g. paraphrasing, re-reading, questioning). They also suggested that teachers should teach deep level reading strategies into their reading instruction. Yet another interesting article that aimed to see whether reading skills moderate the effect of strategy training for learning with hypertext, Naumann et al. (2008) found that strategy learning affects skilled readers positively but less skilled readers negatively.

In a descriptive study, Klinger et al. (2010) observed some 124 sessions of 41 teachers. They found that in most lessons there was no comprehension instruction, or it was restricted to very simple strategies that prompt students to self-monitor and reflect before, during, and after reading. They went on to conclude that teachers should provide explicit instruction instead of just providing comments about thinking. They also cited that metacognitive strategies are the most important ones to be learnt.

Tsai et al. (2010) compared strategy use between Chinese students when reading in both their native and foreign language. They found despite the fact that students' use of strategy doesn't differ significantly between skilled and less skilled readers in their first language, it showed a significant difference in favor of skilled readers when reading texts in the foreign language. Their findings supported notion of Cohen (1998) that teaching strategy use can help to enhance students' performance in learning the language. In an exploratory study conducted by McNail (2010), the relationship among background knowledge, reading comprehension strategies and second language reading comprehension was investigated. He found that background knowledge is not a strong contributor to reading comprehension, instead selfquestioning is important.

\section{RESEARCH QUESTIONS}

1. Is there a relationship between explicit reading strategies instruction and learners' understanding of reference in readings?

2. Is there a relationship between explicit reading strategies instruction and learners' understanding of conjunction in readings?

3. Is there a relationship between explicit reading strategies instruction and learners' understanding of lexical cohesion in readings? 
4. Is there a relationship between explicit reading strategies instruction and learners' understanding of ellipsis in readings?

5. Is there a relationship between explicit reading strategies instruction and learners' understanding of substitution in readings?

\section{METHODOLOGY}

\section{A. Participants}

40 Persian learners of English participated in the study. It was assumed that students' proficiency level might affect the results of the study; so, the learners of intermediate level were selected. They had just started book three $(=$ the green book) of Interchange series written by Jack C. Richards. Both males (=18) and females $(=22)$ attended the study. All the participants were adults between 21 and 27 years of age who were either university students or university graduates. They were assigned to two groups: one control (=21 participants) and one experimental (=19). Both groups' sessions were held in the same class room at the same time; so, extraneous variables were controlled. Control group's classes were held on even days, from 6 until 9:15 p.m. and Experimental groups' classes were held on odd days, from 6 to 9:15 p.m. Again, to reduce the effect of extraneous elements, the teacher of both classes was the same (the researcher). The researcher did his best to keep everything the same in both classes; except for the independent variable.

\section{B. Material}

The third volume of the Interchange series (the green book) was used for the method of the classroom. Every aspect of the teaching, including the time devoted to each task, was held as constant as possible. No other material was used in the experimental group more than what was used in the control group. The only difference was at the instruction of the reading comprehension part which was at the end of each lesson. In order to measure students' performance in our area of interest, two tests were developed that each contained 50 items; 10 items for each subcategory. Items were selected carefully from TOEFL exams to enhance the reliability and validity of the tests.

Three highly experienced English teachers and test developers were asked to review and judge the items to eliminate inappropriate items. Then, items were pooled and 10 of them were selected for each subcategory of each of the two tests. Two tests were piloted and the same time was given to some 30 students with similar characteristics of our groups (intermediate Persian students of English, studying the same book, both male and female).Two tests were highly correlated. The given tests were in written mode and participants had 50 minutes (one minute for each item) to respond. 3 passages were used in each test, and the students were asked to answer 18 questions according to those passages, and the rest of the questions were asked through multiple-choice items. In order to reduce the probability of negative test effects, items in each test were assigned randomly.

\section{Procedure}

Every effort was made to reduce the Hawthorn effect. Two classes were managed and controlled quite alike with the exception of the reading section. In the experimental group, students were explicitly noticed the reading techniques necessary for dealing with the text. They even learnt the names of those strategies. In the control group, however, all those strategies were taught in an implicit way. For example, students in both groups were asked to silently read the passage and underline the words, phrases, or structures that they were not sure about. Then, the teacher went over the passage to clarify and answer students' questions. In the experimental group, the teacher drew students' attention to the strategy that could be used in that situation and situations alike, and named the strategy; while in the control group, the teacher just helped them to somehow figure the meaning out, probably with the strategies they already knew, or a new one but in an implicit way. The students in the control group were not informed about the name of the strategies and they were not told explicitly that each technique can be used in other contexts that are similar.

The pre-test was given to the students at the beginning of the semester. It was given to them along with some other questions that measured other aspects of learning, like listening, speaking, or writing, in order to conceal the aim of the project. The course started three days after the pre-test administration. During the course, the pre-test was not mentioned at all. In order to increase the reliability of the scores, 10 items were included to measure each subcategory. The post-test had the same categories and characteristics. It was administrated 7 days after the course finished in order to reduce instant and short term effects of the treatment. Students regarded the test as their final exam and so did their best to answer the items. All the administrations' conditions were tried to be the same or at least alike.

We used concurrent validation to check out the validity and reliability of these two tests: they were given to a population with characteristics similar to those of our target population. Some 16 students who were at the same level were picked and asked to answer all the 100 items which had appeared in the two tests. Students were exposed to 90 complete hours of instruction during which the teacher covered the third book of interchange series (the intermediate course in which the book with the green cover is taught). The course took 10 and the experiment 11 weeks to finish. About 12 hours of the whole class time, directly or indirectly, was related to reading and its related strategies.

D. Analysis 
In order to investigate the amount of correlation between the two exams, Pearson correlation coefficient was used. Two sample T-test was exploited to investigate the similarity of control and experimental group and also the amount of effectiveness of the proposed method in comparison with the method used in control group. All the assumptions of using a parametric test were considered and met. The scores formed a normal distribution and they were not dependent on each others. The data were interval as well. The effect of one variable was being investigated; so, the appropriate statistical test was chosen: t-test. More information is brought in the results section.

\section{E. Results}

In order to investigate the amount of correlation between the tests, they were given to some 16 students and each of them got two scores out of 50. The results show that the correlation between two tests is 0.81 which is acceptable. The mean of the scores of the first and second test were 25.5 and 26.31 respectively. The results have been shown in the table 1 below:

TABLE 1

CORRELATIONS

\begin{tabular}{|ll|l|l|}
\hline \multicolumn{2}{|l|}{ VAR00006 } & VAR00006 & VAR00007 \\
& Pearson Correlation & 1 & $.805^{* *}$ \\
& Sig. (2-tailed) & & .000 \\
& $\mathrm{~N}$ & 16 & 16 \\
\hline VAR00007 & Pearson Correlation & $.805^{* *}$ & 1 \\
& Sig. (2-tailed) & .000 & \\
& $\mathrm{~N}$ & 16 & 16 \\
\hline & $* *$ Correlation is significant at the 0.01 level (2-tailed).
\end{tabular}

**. Correlation is significant at the 0.01 level (2-tailed).

In order to find out if there is a significant difference between the students of control and experimental group; two sample T-test were used. Students were divided into two groups: one control and another experimental. The following hypothesis was defined:

$\mathrm{H}_{0:} \mu_{1=} \mu_{2}$

$\mathrm{H}_{0:} \mu_{1 \neq} \mu_{2}$

$\mathrm{H}_{0}$ states that there is no significant relationship between the levels of knowledge of the two groups. The results, using the two sample t-test, have been shown in table 2:

TABLE 2

GROUP STATISTICS

\begin{tabular}{|ll|l|l|l|l|}
\hline & Group & $\mathrm{N}$ & Mean & Std. Deviation & Std. Error Mean \\
\hline Sumpretest & Group1 & 21 & 24.6190 & 2.55883 & .55838 \\
& Group2 & 19 & 24.3158 & 2.13574 & .48997 \\
\hline
\end{tabular}

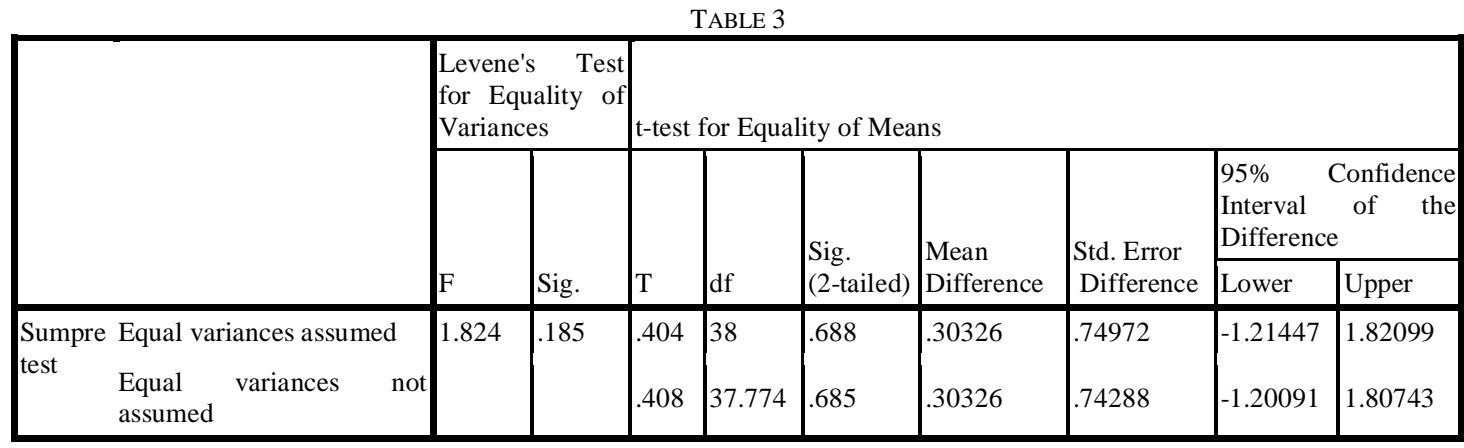


TABLE 4

Group STATISTICS

\begin{tabular}{|ll|l|l|l|l|}
\hline \multirow{2}{*}{ Test1 } & Group & $\mathrm{N}$ & Mean & Std. Deviation & Std. Error Mean \\
& Group1 & 21 & 1.0952 & .76842 & .16768 \\
& Group2 & 19 & 1.7368 & 1.14708 & .26316 \\
\hline Test2 & Group1 & 21 & .9524 & .97346 & .21243 \\
& Group2 & 19 & 1.4737 & .61178 & .14035 \\
\hline Test3 & Group1 & 21 & 1.2857 & 1.10195 & .24046 \\
& Group2 & 19 & 1.5789 & .60698 & .13925 \\
\hline Test4 & Group1 & 21 & 1.2381 & .88909 & .19401 \\
& Group2 & 19 & 2.3684 & 1.53516 & .35219 \\
\hline Test5 & Group1 & 21 & .9048 & 1.04426 & .22788 \\
& Group2 & 19 & 2.0000 & 1.05409 & .24183 \\
\hline
\end{tabular}

According to the acquired results, $\mathrm{F}$ equals 1.824 and the significance level is 0.185 . Regarding the fact that the significance level is bigger than 0.05 , there is no significant difference between two groups at the beginning of the study.

In order to investigate if there is a significant difference between two methods, two sample t-test was used. The differences between their students' levels have been recorded through pre and post test. Accordingly, the below hypothesis was defined:

$\mathrm{H}_{0:} \mu_{1=} \mu_{2}$

$\mathrm{H}_{0:} \mu_{1 \neq} \mu_{2}$

$\mathrm{H}_{0}$ hypothesis states that there is no significant difference between two methods. The results have been shown in table 4 and 5. The results show that there is a significant difference in factors one and four: significance numbers are 0.011 and 0.014 , respectively. Significance value and T statistic in both above factors are 0.043 and 0.006 with the assumption of equality of means. Upper and lower limits in factor 1 are -1.261 and -0.221 , respectively that shows the mean of difference of the scores in the second method is bigger than its counterpart in first method. Lower and upper limits in factor four are -1.924 and -0.337 that shows the mean of difference of the scores in the second method is bigger than its counterpart in first method.

About factor 3, despite the fact that the assumption of the equality of variances is rejected; the significance value of T statistic is 0.311 that shows there is no significant difference between two methods for the factor 3 . The assumption of the equality of the variances is not rejected for factors 2 and 5. There is, however, no significant difference between two methods for these two factors.

TABLE 5

AMPLES TEST

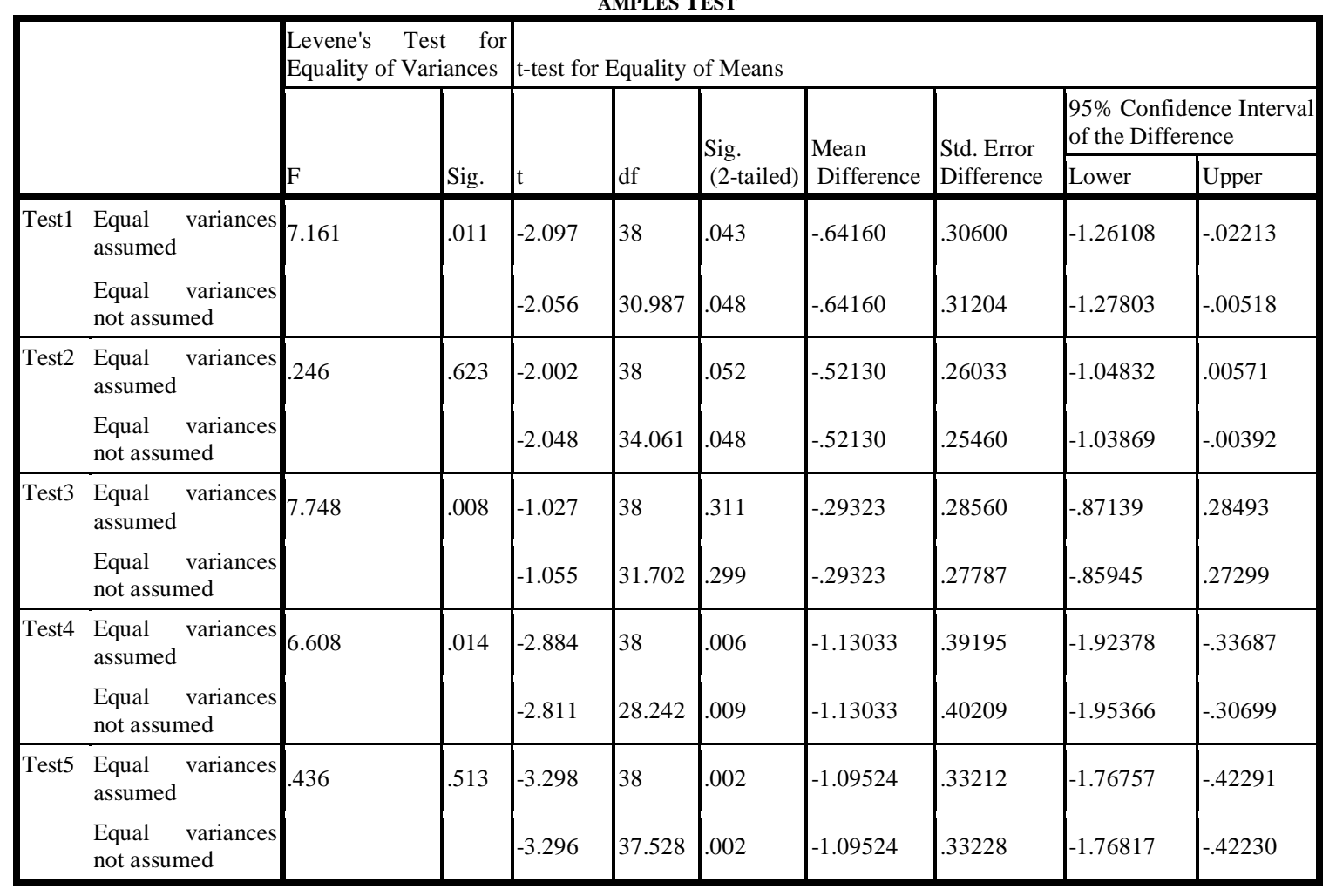




\section{CONCLUSIONS}

In this study, we investigated the effect of explicitly instruction of reading strategies in comparison with implicitly instruction of reading strategies on Students' Understanding of Cohesion in Reading. We considered all of its subcategories that include: Reference, ellipsis, conjunction, substitution, and lexical cohesion. The results revealed that the proposed method was only effective for items 1 (reference) and 4 (ellipses). So, it is suggested that further researches focus on finding some ways to improve the remaining items. Also, further research could be led to investigate other aspects of reading except for cohesion. This study only included the intermediate students and the findings might not be applicable to other levels.

\section{REFERENCES}

[1] Boulware-Gooden, R. Carreker, S. Thornhill, A. Joshi, R.M. (2007). Instruction of metacognitive strategies enhances reading comprehension and vocabulary achievement of third-grade students. The Reading Teacher, 61(1), 70-77.

[2] Brown, H.D. (2005). Principles of language learning and teaching ( $5^{\text {th }}$ ed.). New York, NY: Pearson Education Company.

[3] Cohen, A. (1998). Strategies in learning and using a second language. London: Longman.

[4] Cornaldi, C. \& Oakhill, J. (1996). Reading comprehension difficulties: Processes and intervention. Mahwah, NJ: Erlbaum.

[5] Griffith, C. (2003). Patterns of language learning strategy use. System, 31, 367-383.

[6] Halliday, M. \& Hassan, R. (1994). Cohesion in English. Longman: Longman

[7] Klinger, J.K., Urbach, J., Golos, D., Brownell, M., \& Menon, Sh. (2010). Teaching reading in the $21^{\text {st }}$ century: A glimpse at how special education teachers promote reading comprehension. Learning Disability Quarterly, 33, 59-74.

[8] Lau, K.L., \& Chan, D.W. (2003). Reading strategy use and motivation among Chinese good and poor readers in Hong Kong. Journal of Research in Reading, 26(2), 177-190.

[9] Long, D. L., Oppy, B. J., \& Seely, M. R. (1994). Individual differences in the time course of inferential processing. Journal of Experimental Psychology: Learning, Memory, and Cognition, 20, 1456-1470.

[10] Mayor, M. (2009). Longman dictionary of contemporary English ( $5^{\text {th }}$ ed.). Edinburgh: Pearson Publisher.

[11] McNail, L. (2010). Investigating the contributions of background knowledge and reading comprehension strategies to L2 reading comprehension: an exploratory study. Read Writ, 09, In Press.

[12] McNamara, D.S., O’Reilly, T.P., Best, R.M., \& Ozuru, Y. (2006). Improving adolescent students' reading comprehension with iSTART. Journal of Educational Computing Research, 34(2), 147-171.

[13] McNamara, D. S., \& McDaniel, M. (2004). Suppressing irrelevant information: Knowledge activation or inhibition?. Journal of Experimental Psychology: Learning, Memory, \& Cognition, 30, 465-482.

[14] Naumann, J., Richter, T., Christmann, U., \& Groeben, N. (2008). Working memory capacity and reading skill moderate the effectiveness of strategy training in learning from hypertext. Learning and Individual Differences, 18, 197-213.

[15] Oakhill, J., \& Yuill, N. (1996). Higher order factors in comprehension disability: Processes and remediation. In C.

[16] Pani, S. (2003). Reading strategy instruction through mental modeling. ELT Journal, 58(4), 355-362.

[17] Rao, J., Gu, P.Y., Zhang, L.J., \& Hu, G. (2007). Reading strategies and approaches to learning of bilingual primary school pupils. Language Awareness, 16(4), 243-262.

[18] Tsai, Y.R., Ernst, Ch., \& Talley, P.C. (2010). L1 and L2 strategy use in reading comprehension of Chinese EFL readers. Reading Psychology, 31, 1-29

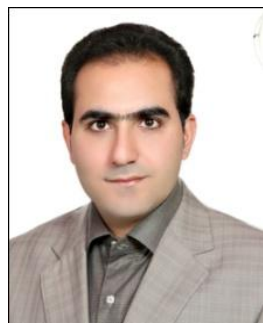

Ali Mobalegh (b. 1982, Isfahan, Iran) received his M.A. in TEFL from the University of Isfahan, Isfahan, Iran (2008) following the completion of his B.A. in English Literature at the same university (2005). His main research areas of interest are: English Language Testing, Language Teaching Methodology. He has been working as an EFL instructor since 2000.

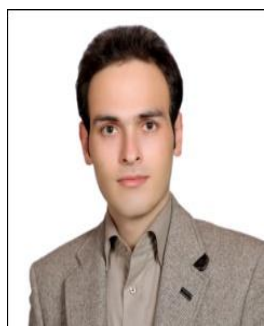

Mohammad Saljooghian (b. 1984, Isfahan, Iran) is currently a Master from the University of Tehran Payam-e-Noor, Tehran, Iran. His main research areas of interest are: English Language Teaching Methodology and Pragmatics. He has been working as an EFL instructor since 2002. 